\title{
Novel bis-phenanthridine derivatives with easily tunable linkers, study of their interactions with DNA and screening of antiproliferative activity
}

\author{
Marko Dukši,$^{\text {a,b }}$ Domagoj Baretić, ${ }^{a}$ Vesna Čaplar, ${ }^{\mathrm{a}}$ Ivo Piantanida ${ }^{\mathrm{a} *}$

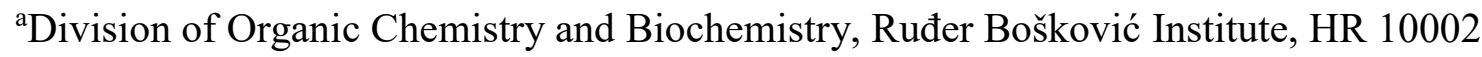 \\ Zagreb, Croatia; Fax: +385 1 4680195; E-mail: pianta@irb.hr \\ ${ }^{\mathrm{b}}$ GlaxoSmithKline Research Centre Zagreb, Prilaz Baruna Filipovića 29, 10000 Zagreb, \\ Croatia
}

\begin{abstract}
Series of novel peptide-bridged bis-phenanthridine derivatives as well as corresponding monomers were prepared by solid phase peptide synthesis, which allowed easy and fast tuning of compound properties. Interactions of new derivatives with double stranded DNA were strongly structure-dependent, among which the most interesting is bisphenanthridine derivative forming intramolecular excimer, with specific fluorescence band sensitive to the $\mathrm{pH}$ as well as on the interactions with ds-DNA. Moreover, at variance to commonly high cytotoxic effects of phenanthridine derivatives, here studied monomeric as well as bis-phenanthridine derivatives exhibited negligible antiproliferative activity on a panel of human cell lines, which makes them promising lead compounds for development of new spectrophotometric markers.
\end{abstract}

\section{Introduction}

Very recently, even thoroughly studied molecules as classical DNA/RNA intercalator and marker ethidium bromide had to be re-evaluated, since it became obvious that mechanisms of non-covalent interactions between small molecule and DNA/RNA are not completely understood.[1-3] In addition, it was shown that the chemical modulation of the ethidium substituents is a profitable option to tune the nucleic acid recognition properties of phenanthridine dyes.[4] Very recent reports about numerous applications point toward versatility of the phenanthridine core, [5-9] including even intriguing biological activity.[10] A huge number of bis-phenanthridine derivatives were prepared with the aim of not only

\footnotetext{
* Corresponding author. Tel.: +385 14571 326; fax: +385 14680 195; e-mail: pianta@irb.hr
} 
enhanced affinity due to the bis-intercalation into DNA/RNA but also with the idea of introducing selectivity.[11] Moreover, some bis-phenanthridine compounds have shown at the time the highest binding constants for nucleotides but not selectivity among studied nucleobases.[12] Our recent results have pointed out that selectivity of bis-phenanthridine derivatives toward various DNA/RNA sequences could be controlled by the steric effects[13,14] or by electrostatic interactions with DNA/RNA backbone and/or nucleobases.[15,16] However, the efforts to upgrade already promising molecules quite often led to longer and more complicated synthetic pathways. Therefore, the strategy of convergent synthesis, which will retain structural features of successful molecules but allow significantly easier and faster modulation of active structure, would allow fine tuning of selectivity and/or other tasks of a novel, small molecules to be done by reasonable time and effort investment. Here we present easy and fast synthesis of novel peptide-bridged bis-phenanthridine derivatives and corresponding monomers (Scheme 1), study of their physical and chemical properties in aqueous medium as well as their interactions with double stranded (ds-) DNA.

\section{Scheme 1.}

\section{Results and Discussion}

As a synthetic route to an easily variable spacer backbone, we used solid phase peptide synthesis procedures [17]. The most prominent advantages of proposed approach are: a) an easy preparation of novel amino acid-phenanthridine monomer; b) oligomerisation of monomers can be easily controlled by means of order, chirality of linker, distance between monomers; c) simple and fast preparation of new generations of compounds by modification of the last (oligomerisation) step.

Scheme 2.

Interestingly, solubility of $\mathbf{1 - 5}$ in water at neutral conditions $\left(c \approx 1 \times 10^{-3} \mathrm{M}\right)$ is significantly higher than solubility of previously studied bis-phenanthridines, $[12,15 \mathrm{~b}]$ most likely due to the influence of carboxylic groups present only in $\mathbf{1} \mathbf{- 5}$.

The UV-Vis spectra of compounds $\mathbf{1}$ - $\mathbf{5}$ were $\mathrm{pH}$ dependent, exhibiting a one step change at about $\mathrm{p} K_{a} \approx 6$, attributed to the protonation of phenanthridine heterocyclic nitrogen.[18-20] To compare properties of neutral and protonated form of phenanthridine, all further experiments were done at $\mathrm{pH} 7$ and $\mathrm{pH}$, respectively. Comparison of the UV-Vis 
spectra revealed only minor differences between protonated $(\mathrm{pH} \mathrm{5)}$ and neutral $(\mathrm{pH} 7)$ form of compounds 1-5. A comparison of the UV-Vis spectra (Figure 1) revealed high similarity of spectra of $\mathbf{1}$ and 2, pointing toward negligible contribution of absorbance of glycine in 2 . Interestingly, the molar absorbencies (Figure 1) of bis-phenanthridine derivatives $\mathbf{3}$ and $\mathbf{4}$ are much lower than sum of UV-Vis spectra of two monomers $(\mathbf{1}+\mathbf{1}$ in comparison to $\mathbf{3}$ and $\mathbf{1}+\mathbf{2}$ in comparison to 4). Such a hypochromic effect strongly suggests intramolecular aromatic stacking interactions between phenanthridine subunits of $\mathbf{3}$ and 4 . Although the molar absorbance of bis-phenanthridine $\mathbf{5}$ is lower than sum of UV-Vis spectra of two monomers $(\mathbf{2}+\mathbf{2})$, hypochromic effect is much less pronounced in comparison to $\mathbf{3}$ and $\mathbf{4}$, pointing that introduction of two glycines between phenanthridine subunits significantly reduced efficiency of intramolecular aromatic stacking interactions.

Figure 1.

Compounds 1 - 5 exhibit strong fluorescence emission of phenanthridine chromophore (Figure 2). Fluorescence spectra of $\mathbf{1 , 2}, \mathbf{4}, \mathbf{5}$ are quite similar, while spectrum of $\mathbf{3}$ is significantly different at both, $\mathrm{pH} 5$ and 7. Most intriguingly, at $\mathrm{pH} 7$ fluorescence spectrum of $\mathbf{3}$ is characterized by two maxima, one at $\lambda=375 \mathrm{~nm}$ (agreeing well with emission maxima of $1,2,4,5)$ and other maximum strongly shifted to longer wavelengths $\left(\Delta \lambda=+93 \mathrm{~nm}, \lambda_{\max }=\right.$ $468 \mathrm{~nm}$ ) in respect to other studied compounds. At pH 5 two emission maxima of 3 are not well separated, most likely due to the protonation of phenanthridines, which affected intramolecular aromatic stacking interactions. However, broad maximum at about $\lambda=440 \mathrm{~nm}$ is still significantly shifted to longer wavelengths $(\Delta \lambda=+40 \mathrm{~nm})$ in respect to $\mathbf{1 , 2 , 4 , 5}$.

Figure 2.

CD spectroscopy: All studied compounds are chiral due to the asymmetric carbon atom of substituted L-alanine. Turbidity of solutions of several compounds at $\mathrm{pH} 7$ hampered collection of accurate CD spectra, while better solubility of $\mathbf{1}-\mathbf{5}$ at $\mathrm{pH} 5$ (due to the protonation of phenanthridine) allowed accurate comparison of their CD spectra (Figure 3). Although phenanthridine chromophore is not chiral, in compounds $\mathbf{1}-\mathbf{5}$ it is closely related to chiral centre, therefore positive CD bands of $\mathbf{1}$ and $\mathbf{2}$ at $250 \mathrm{~nm}$ agree well with the maxima in the $\mathrm{UV} / \mathrm{Vis}$ spectra of $\mathbf{1}, \mathbf{2}$ and consequently could be attributed to the phenanthridine. 
Figure 3.

However, CD spectra of bis-phenanthridine derivatives 4, 5 and especially 3 significantly differ from the CD spectra of monomers $(\mathbf{1}, \mathbf{2})$. The CD spectra of $\mathbf{3}$ and $\mathbf{5}$ are characterized by negative band at about $270 \mathrm{~nm}$ and in addition exclusively 3 revealed significant hypsochromic shift of positive CD band $(\Delta \lambda=-13 \mathrm{~nm})$ in respect to all other compounds. Most intriguingly, CD spectrum of $\mathbf{4}$ is of opposite (negative) sign in respect to 1, 2, 3 and 5 at $\lambda<240 \mathrm{~nm}$ and also opposite (positive) sign to 3 and $\mathbf{5}$ at $\lambda>270 \mathrm{~nm}$. The additional CD band of 3-5 at $\lambda>270 \mathrm{~nm}$ (which monomers 1, 2 do not possess) could be attributed to the induced CD (ICD) effect resulting from intramolecular interactions of phenanthridine subunits, whereby opposite sign of CD spectrum of $\mathbf{4}$ in respect to $\mathbf{3}$ and $\mathbf{5}$ suggests different mutual orientation of phenanthridine subunits.

\section{Discussion of spectroscopic properties of 1-5:}

Hypochromic effect in the UV-Vis spectra suggests intramolecular aromatic stacking interaction in dimers (3-5). However, a specific fluorescence maximum of $\mathbf{3}$ in respect to other bis-phenanthridine derivatives $(4,5)$ could be correlated to the properties of the linker between phenanthridine subunits, which is in the case of $\mathbf{3}$ significantly shorter and more rigid if compared to linkers of $\mathbf{4}, \mathbf{5}$. Consequently, phenanthridine subunits of $\mathbf{3}$ could form highly efficient intramolecular stacking interactions, whereby mutual orientation of aromatic moieties is strictly controlled by rigid linker and therefore most likely one dominant form of stacked conformation prevails. Presumed difference of intramolecular stacked conformation of $\mathbf{3}$ in respect to $\mathbf{4}$ and $\mathbf{5}$ is additionally supported by pronounced differences in the corresponding CD spectra. Most intriguingly, it seems that electronic properties of intramolecularly stacked conformation of $\mathbf{3}$ are characterized by specific fluorescence maximum, which is strongly shifted to longer wavelengths in respect to monomers $(\mathbf{1}, \mathbf{2})$ and dimers with longer and more flexible linkers $(\mathbf{4}, \mathbf{5})$. Very similar change in fluorescence is well described for pyrene, $\left[21,{ }^{22}\right]$ namely fluorescence of single pyrene molecule $\left(\lambda_{\max }=378\right.$ and $391 \mathrm{~nm})$ is significantly shifted to longer wavelengths $\left(\lambda_{\max }=450-480 \mathrm{~nm}\right)$ upon aromatic stacking of two or more pyrene molecules and formation of an pyrene excimer.

Interactions of 1-5 with ct-DNA: 
The UV-Vis spectra of compounds $\mathbf{1 , 2}$ exhibited strong hypochromic changes as well as pronounced batochromic shifts of the absorption maxima upon titration with ct-DNA (Figure 4), pointing toward involvement of $\mathbf{1 , 2}$ into strong $\pi-\pi$ aromatic stacking interactions with DNA. Isosbestic points strongly suggest that both, $\mathbf{1}$ and $\mathbf{2}$, form only one dominant type of complex with ct-DNA. The changes of 3-5 UV-Vis spectra at $\lambda>300 \mathrm{~nm}$ upon mixing with ct-DNA are significantly less pronounced than $\mathbf{1}$ and $\mathbf{2}$.

Figure 4.

Addition of ct-DNA to 1-5 at both, $\mathrm{pH} 7$ and $\mathrm{pH} \mathrm{5,} \mathrm{resulted} \mathrm{in} \mathrm{strong} \mathrm{quenching} \mathrm{of} \mathrm{their}$ fluorescence (Figure 5). Processing of titration data by means of Scatchard equation [23] gave $\log K s$ values (Table 1). Somewhat higher affinity of all studied compounds toward ct-DNA was obtained at $\mathrm{pH} 5$ than at $\mathrm{pH} 7$, which could be attributed to additional binding contribution of positive charge of phenanthridine units protonated at weakly acidic conditions. Furthermore, dimers 3-5 revealed stronger affinity toward ct-DNA than monomers $\mathbf{1}$ and $\mathbf{2}$, most likely due to the simultaneous involvement of both phenanthridine subunits in binding. Intriguingly, titration with ct-DNA resulted in pronounced hypsochromic shift of emission maximum of 3 (Figure $5 \mathrm{~B}, \Delta \lambda \approx-30 \mathrm{~nm}$ ). The resulting fluorescence spectrum of 3/ct-DNA complex closely resembled to the spectra of monomers $\mathbf{1}$ and $\mathbf{2}$ bound to ct-DNA (Figure 5A). Such a change of emission spectrum could be attributed to the DNA-induced dissociation of intramolecular excimer of $\mathbf{3}$.

Figure 5.

Table 1.

In order to get better insight into the changes of polynucleotide properties induced by binding of 1-5, we have chosen CD spectroscopy as a highly sensitive method toward conformational changes in the secondary structure of polynucleotides.[24,25] Comparison of the CD spectra collected at ratio $\mathrm{r}_{[\text {compd] } /[\mathrm{ct}-\mathrm{DNA}]}=0.3$ and the sum of corresponding $\mathrm{CD}$ spectra of the free ct-

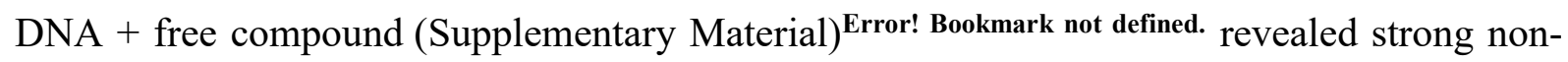
additivity and actually pronounced hypochromic effect in respect to both, CD spectra of free DNA and free 1-5. Such a pronounced effect pointed toward significant changes in chiral 
structures of both, DNA and studied compounds induced by complex formation.

Table 2.

Addition of 1-5 yielded outstandingly different stabilization effects on thermal denaturation of ct-DNA double helix (Table 2). Interestingly, monomer 2 significantly stronger stabilized DNA double helix than 1, pointing that glycine of $\mathbf{2}$ also contributed to stabilizing interactions. Furthermore, strongly nonlinear dependence of $\Delta T m$ values on the ratio $\boldsymbol{r}$

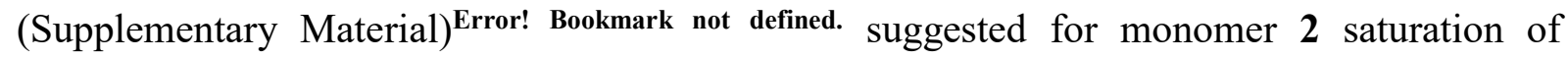
binding sites at $\boldsymbol{r}=0.3$, whereby nonlinear dependence of $\Delta T m$ values on the ratio $\boldsymbol{r}$ pointed that binding sites of dimer 3 were already saturated at $r=0.2$. Since at saturation of binding sites the $\Delta T_{m}$ values of $\mathbf{2}$ and $\mathbf{3}$ are virtually the same, dominant interaction with ct-DNA could be attributed to the only one phenanthridine unit, whereby other phenanthridine unit of 3 is stacked to the outer surface of DNA, in that way lowering the density of binding sites. Dimers 4 and 5 yielded $\Delta T_{m}$ values more than double in comparison to $\Delta T_{m}$ value obtained for monomer 2, pointing toward simultaneous involvement of both phenanthridine subunits of 4 and $\mathbf{5}$ in the ct-DNA stabilization.

\section{Biological Results and Discussion}

In general, representatives of tested compounds (1 and 4) didn't show any growth inhibitory activity on the presented panel of cell lines (Table 3), which contradicts commonly high cytotoxic effects of phenanthridine derivatives.

Table 3 .

The observed lack of citotoxicity most likely could be attributed to the attached amino acid substituents to the phenanthridine subunits. It could be speculated that compounds, which are negatively charged (amino acid carboxylic residues) at common physiological conditions of $\mathrm{pH}=7$ ( $\mathrm{pKa}=6$ of phenanthridine dictates protonation and positive charge at $\mathrm{pH} 5$ ) either less efficiently cross cell membrane or (more likely) show diminished affinity toward cellular DNA, whereby the exact reason has to be determined in more detailed biological studies.

\section{Conclusions}

Series of peptide-bridged bis-phenanthridine derivatives (3-5) and corresponding 
monomers $(\mathbf{1}, \mathbf{2})$ were prepared by approach based on solid phase peptide synthesis procedures. The advantages in respect to commonly used synthesis[11,12,15] were demonstrated by easy and efficient modulation of bis-phenanthridine structure starting from the only two building blocks (glycine and phenanthridine-L-alanine), which allowed simple tuning of the cavity size between phenanthridine subunits as well as intramolecular rigidity of compounds. Spectrophotometric studies revealed that in biologically relevant medium bisphenanthridine derivatives exhibit significant intramolecular interactions strongly dependent on the rigidity and length of the peptide linker. Moreover, to the best of our knowledge, bisphenanthridine $\mathbf{3}$ is the first phenanthridine derivative exhibiting specific fluorescence signal, which could be most likely attributed to the intramolecular excimer formation. Even more, that fluorescence signal of $\mathbf{3}$ showed to be sensitive on the $\mathrm{pH}$ of solution as well as on the interactions with ds-DNA. Corresponding properties of pyrene were quite extensively applied for several purposes[21-28] and 3 brought new features to it, possessing heterocyclic nitrogen prone to protonation at weakly acidic conditions $(\mathrm{pKa} \approx 6)$. Furthermore, strong batochromic and hypochromic effects in the 1-5 UV/Vis spectra, pronounced hypochromic effects in the CD spectra (of both, ct-DNA and 1-5), high affinity toward ct-DNA as well as pronounced thermal stabilization effects strongly support the intercalation of 1-5 into ct-DNA as a dominant binding mode. Significantly stronger thermal stabilization effects of dimers $\mathbf{4}$ and $\mathbf{5}$ in respect to monomer 2 point toward simultaneous involvement of both phenanthridine subunits of $\mathbf{4}$ and 5; whether due to the bis-intercalation or because of mono-intercalation accompanied by additional interactions of the non-intercalated phenanthridine subunit along the DNA double helix, it still remains to be determined. Moreover, at variance to the most of phenanthridine derivatives, preliminary studies indicated insignificant antiproliferative activity of 1-5 toward five tumour cell lines. Thus, studied compounds are comparatively safe for handling, and could be good lead compounds for development of safe phenanthridinebased fluorescent markers, whose selectivity could be controlled by linker properties and $\mathrm{pH}$ of a solution.

Acknowledgment: Supports by the Ministry of Science, Education and Sport of Croatia (Project 098-0982914-2918) and GlaxoSmithKline Research Centre Zagreb are gratefully acknowledged. We would also like to thank dr. M. Kralj (Ruđer Bošković Institute, Zagreb, Croatia) for proliferation assays on a panel of cell lines.

Supplementary Material available: Synthesis and characterization of 1-5, additional data about interactions of 1-5 with ct-DNA. 


\section{Experimental}

Materials and Methods:

Synthetic procedures and characterisation of novel compounds 1-5 is given in Supplementary Material.

Calf thymus ct-DNA was purchased from Aldrich, dissolved in Na-cacodylate buffer, $I$ $=0.05 \mathrm{M}, \mathrm{pH}=7$ and additionally sonicated and filtered through a $0.45 \mu \mathrm{m}$ filter.[29] Polynucleotide concentration was determined spectroscopically [30] as concentration of phosphates.

The electronic absorption spectra were obtained on Varian Cary 100 Bio spectrometer, CD spectra were collected on the Jasco J-810 spectrometer and fluorescence spectra were recorded on a Varian Cary Eclipse fluorimeter; all in quartz cuvettes $(1 \mathrm{~cm})$. The $\mathrm{pH}$ measurement was carried out using Mettler TOLEDO MP220 pHmeter calibrated with commercially available buffered aqueous solutions of $\mathrm{pH}$ standards 4.00 and 7.00 . The measurements were performed in aqueous buffer solution $(\mathrm{pH}=7$ - buffer Na cacodylate, $I=$ $0.05 \mathrm{M}, \mathrm{pH}=5$ - buffer citric acid/ $\mathrm{NaOH}, I=0.03 \mathrm{M}$ ). Under the experimental conditions used buffered aqueous solutions of studied compounds were stable for more days, the absorbencies were proportional to concentrations of $\mathbf{1 - 5}$ up to $c=3 \times 10^{-5} \mathrm{M}$, changes of the 1-5 UV/Vis spectra on the temperature increase up to $85{ }^{\circ} \mathrm{C}$ were negligible and reproducibility of UV/Vis spectra upon cooling back to $25{ }^{\circ} \mathrm{C}$ was excellent, indicating that studied compounds do not aggregate by intermolecular stacking at experimental conditions used. In fluorimetric titrations excitation wavelength of $\lambda_{\mathrm{exc}}>300 \mathrm{~nm}$ was used to avoid inner filter effects caused by absorption of excitation light by added ct-DNA. The binding constant $\left(K_{s}\right)$ and [bound 1-5] / [DNA phosphate] ratio $(n)$ were calculated according to the Scatchard equation by nonlinear least-square fitting, ${ }^{23}$ giving excellent correlation coefficients $(>0.999)$ for obtained values for $K_{s}$ and $n$. Thermal denaturation curves for ct-DNA and its complexes with 1-5 were determined as previously described by following the absorption change at $260 \mathrm{~nm}$ as a function of temperature.[29,30] The absorbance of 1-5 was subtracted from every curve, and the absorbance scale was normalized. Obtained $T_{\mathrm{m}}$ values are the midpoints of the transition curves, determined from the maximum of the first derivative or graphically by a tangent method. Given $\Delta T_{\mathrm{m}}$ values were calculated subtracting $T_{\mathrm{m}}$ of the free nucleic acid from $T_{\mathrm{m}}$ of 
complex. Every $\Delta T_{\mathrm{m}}$ value here reported was the average of at least two measurements, the error in $\Delta T_{\mathrm{m}}$ is $\pm 0.5^{\circ} \mathrm{C}$.

Proliferation assay. The HeLa, MiaPaCa-2, SW 620, MCF-7 and H460 cell lines were seeded into a series of standard 96-well microtiter plates on day 0 , at $1 \times 10^{4}$ to $3 \times 10^{4}$ cells $/ \mathrm{mL}$, depending on the doubling times of the specific cell lines. Test compounds were then added in five, 10 -fold dilutions $\left(10^{-8}\right.$ to $\left.10^{-4} \mathrm{M}\right)$ and incubated for a further 72 hours. Stock solutions were prepared in DMSO, $(c=0.04 \mathrm{M})$, while working dilutions were freshly prepared on the day of testing. The solvent (DMSO) was also tested for eventual inhibitory activity by adjusting its concentration to be the same as in working concentrations (DMSO concentration never exceeded $0.1 \%$ ). After 72 hours of incubation the cell growth rate was evaluated by performing the MTT assay, as described previously.[31]

\section{References}

[1] NW Luedtke, Q Liu, Y Tor, Chem. Eur. J. 11 (2005) 11495.

[2] T Kubar, M Hanus, F Ryjacek, P Hobza, Chem. Eur. J. 12 (2006) 280.

[3]KM Langner, P Kedzierski, WA Sokalski, J. Leszczynski, J. Phys. Chem. B 110 (2006) 9720 .

[4] C Bailly, RK Arafa, FA Tanious, W Laine, C Tardy, A Lansiaux, P Colson, DW Boykin, WD Wilson, Biochemistry 44 (2005) 1941.

[5]A Krasinski, Z Radić, R Manetsch, J Raushel, P Taylor, KB Sharpless, HC Kolb, J. Am. Chem. Soc., 127 (2005) 6686.

[6] ED Horowitz, NV Hud, J. Am. Chem. Soc. 128 (2006) 15380.

[7] I Kock, D Heber, M Weide, U Wolschendorf, B Clement. J. Med. Chem. 48 (2005) 2772.

[8] D Parker, Coord. Chem. Rev. 205 (2000) 109.

[9] V Peytou, R Condom, N Patino, R Guedj, A-M Aubertin, N Gelus, C Bailly, R Terreux, D Cabrol-Bass, J. Med. Chem. 42 (1999) 4042.

[10] I Boibessot, CMR Turner, DG Watson, E Goldie, G Connel, A McIntosh, MH Grant, GG Skellern, Acta Tropica 84 (2002) 219.

[11] LPG Wakelin, Med. Res. Rev, 6 (1986) 275.

[12] P Čudić, M Žinić, V Tomišić, V Simeon, J-P Vigneron, J-M Lehn, J. Chem. Soc., Chem. Commun. (1995) 1073.

[13] I Piantanida, BS Palm, P Čudić, M Žinić, H-J Schneider, Tetrahedron Lett., 42 (2001) 6779. 
[14] I Piantanida, BS Palm, P Čudić, M Žinić, H-J Schneider, Tetrahedron, 60 (2004) 6225.

[15] G Malojčić, I Piantanida, M Marinić, M Žinić, M Marjanović, M Kralj, K Pavelić, H-J Schneider, Org. Biomol. Chem., 3 (2005) 4373.

[16] M Radić Stojković, I Piantanida, Tetrahedron, 64 (2008) 7807.

[17] P Chakraborty, U Diederichsen, Chem. Eur. J., 11 (2005) 3207 and ref. therein.

[18] L-M Tumir, I Piantanida, P Novak, M Žinić, J. Phys. Org. Chem. 15 (2002) 599.

[19] L-M Tumir, I Piantanida, I Juranović, Z Meić, S Tomić, M Žinić, Chem. Commun. (2005) 2561.

[20] RL Jones, WD Wilson, Biopolymers, 20 (1981) 141.

[21] JR Lakowicz, In Principles of Fluorescence Spectroscopy, Kluwer Academic/Plenum: New York, 1999.

[22] SS Lehrer, Meth. Enzymol. 287 (1997) 286.

[23] JD McGhee, PH von Hippel, J. Mol. Biol. 103 (1976) 679.

[24] A Rodger, B Norden, in: Circular Dichroism and Linear Dichroism, Oxford University Press: New York, 1997, Chapter 2.

[25] M Eriksson, B Nordén, Meth. Enzymol, 340 (2001) 68.

[26] A Mahara, R Iwase, T Sakamoto, K Yamana, T Yamaoka, A Murakami. Angew. Chem. Int. Ed. 41 (2002) 3648.

[27] I Trkulja, SM Biner, SM Langenegger, R Haner, ChemBioChem. 8 (2007) 25.

[28] NN Dioubankova, AD Malakhov, DA Stetsenko, MJ Gait, PE Volynsky, RG Efremov, VA Korshun, ChemBioChem. 4 (2003) 841.

[29] JB Chaires, N Dattagupta, DM Crothers, Biochemistry. 21 (1982) 3933.

[30] BS Palm, I Piantanida, M Žinić, H-J Schneider, J. Chem. Soc., Perkin Trans. 2. (2000) 385.

[31] M. Hranjec, I. Piantanida, M. Kralj, L. Šuman, K. Pavelić, G. Karminski-Zamola, J. Med. Chem. 51 (2008) 4899. 


\section{Tables}

Table 1. Binding constants $(\log K s)^{\mathrm{a}}$ calculated from the fluorimetric titrations of $\mathbf{1 - 5}$ with ctDNA at $\mathrm{pH}=7.0$ (buffer Na cacodylate, $I=0.05 \mathrm{M}$ ) and $\mathrm{pH}=5.0$ (buffer citric acid/ $\mathrm{NaOH}, I$ $=0.03 \mathrm{M}$ ).

\begin{tabular}{|c|c|c|c|c|}
\hline & \multicolumn{2}{|c|}{$\mathrm{pH}=7.0$} & \multicolumn{2}{|c|}{$\mathrm{pH}=5.0$} \\
\hline & $\log K s$ & ${ }^{\mathrm{b}} \mathrm{I} / \mathrm{I}_{0}$ & $\log K s$ & ${ }^{\mathrm{b}} \mathrm{I} / \mathrm{I}_{0}$ \\
\hline 1 & 4.5 & 0.1 & 5.4 & 0.10 \\
\hline 2 & 4.7 & 0.07 & 5.5 & 0.19 \\
\hline 3 & $\mathrm{c}$ & $\mathrm{c}$ & 6.7 & 0.20 \\
\hline 4 & 6.0 & 0.08 & 6.9 & 0.08 \\
\hline 5 & 5.4 & 0.59 & 5.9 & 0.19 \\
\hline
\end{tabular}

aProcessing of titration data by means of Scatchard equation [23] gave values of ratio $\mathrm{n}$ [bound 1-5] $/$ ct-DNA] $=0.2-0.3$, for easier comparison all $\log K s$ values were re-calculated for fixed $\mathrm{n}=0.2 ;{ }^{\mathrm{b}} \mathrm{I}_{0}-$ starting fluorescence intensity of $\mathbf{1}-\mathbf{5}$; I - fluorescence intensity of 1-5/ct-DNA complex calculated by Scatchard equation. ${ }^{\mathrm{c}}$ Too small spectroscopic changes $\left(\mathrm{I} / \mathrm{I}_{0}=0.85\right)$.

Table 2. The ${ }^{\mathrm{a}} \Delta T m$ values $\left({ }^{\circ} \mathrm{C}\right)$ of ct-DNA upon addition of different ratios ${ }^{\mathrm{b}} \boldsymbol{r}$ of $\mathbf{1 - 5}$ at $\mathrm{pH}=$ 5.0 (buffer citric acid/NaOH, $I=0.03 \mathrm{M}$ ).

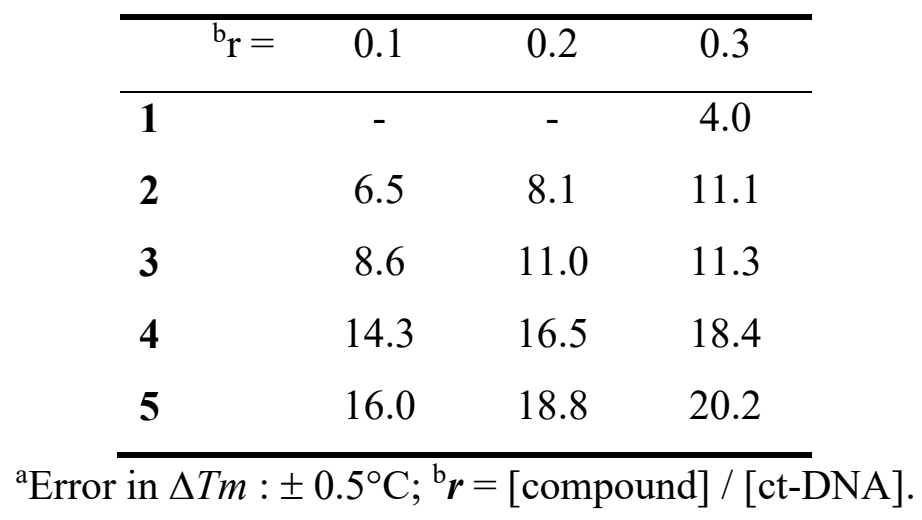


Table 3. Tumour cell growth inhibition presented as $\mathrm{IC}_{50}$ values (in $\mu \mathrm{M}$ ).

Compound

Cell lines

HeLa MiaPaCa-2 SW 620 MCF-7 H 460

\begin{tabular}{rrrrrr}
\hline 1 & $>100$ & $>100$ & $>100$ & $>100$ & $>100$ \\
4 & $>100$ & $\geq 100$ & $>100$ & $>100$ & $>100$ \\
\hline
\end{tabular}

a $\overline{\mathrm{IC}_{50} \text {; the concentration that causes } 50 \% \text { growth inhibition }}$

\section{Figure legends}

Scheme 1. Prepared bis-phenanthridine derivatives 3-5 and corresponding monomers 1, 2.

Scheme 2. A general procedure of applied solid phase synthesis, details are given in the Supporting information.

Figure 1. The UV-Vis spectra of 1-5 at: A) $\mathrm{pH}=7.0$ (buffer Na cacodylate, $I=0.05 \mathrm{M}$ ); B) $\mathrm{pH}=5.0$ (buffer citric acid/NaOH, $I=0.03 \mathrm{M})$.

Figure 2. The fluorescence emission spectra of 1-5 at: at: A) $\mathrm{pH}=7.0$ (buffer Na cacodylate, $I$ $=0.05 \mathrm{M}) ; \mathrm{B}) \mathrm{pH}=5.0($ buffer citric $\operatorname{acid} / \mathrm{NaOH}, I=0.03 \mathrm{M})$. Experimental conditions: $c(\mathbf{1}-$ 5) $=2-6 \times 10^{-6} \mathrm{M}$, different parameters of the instrument were adjusted to give similar intensity of emission maxima, therefore presented fluorescence intensities cannot be directly compared.

Figure 3. The $\mathrm{CD}$ spectra of $\mathbf{1 - 5}$ at $\mathrm{pH}=5.0$ (buffer citric acid/NaOH, $I=0.03 \mathrm{M}$ ).

Figure 4. The UV-Vis titration of $\mathbf{1}(\mathrm{A}, c=2.0 \times 10-5 \mathrm{M})$ and $\mathbf{2}\left(\mathrm{B}, c=2.0 \times 10^{-5} \mathrm{M}\right)$ with ctDNA $\left(c=0-6.0 \times 10^{-4} \mathrm{M}\right), \mathrm{pH}=7.0$, buffer Na cacodylate, $I=0.05 \mathrm{M}$. At the $\mathrm{pH}=5.0$ (buffer citric acid/ $\mathrm{NaOH}, I=0.03 \mathrm{M}$ ) similar results were obtained.

Figure 5. Fluorimetric titration of 1 with ct-DNA and fitting of the experimental ( $\square$ ) and calculated (-) data [23] (A); Fluorimetric titration of $\mathbf{3}$ with ct-DNA (B). Done at $\mathrm{pH}=5.0$, buffer citric acid $/ \mathrm{NaOH}, I=0.03 \mathrm{M}, \lambda$ exc $=320 \mathrm{~nm}, c($ compound $)=2 \times 10^{-6} \mathrm{M}$. 
Figures and schemes

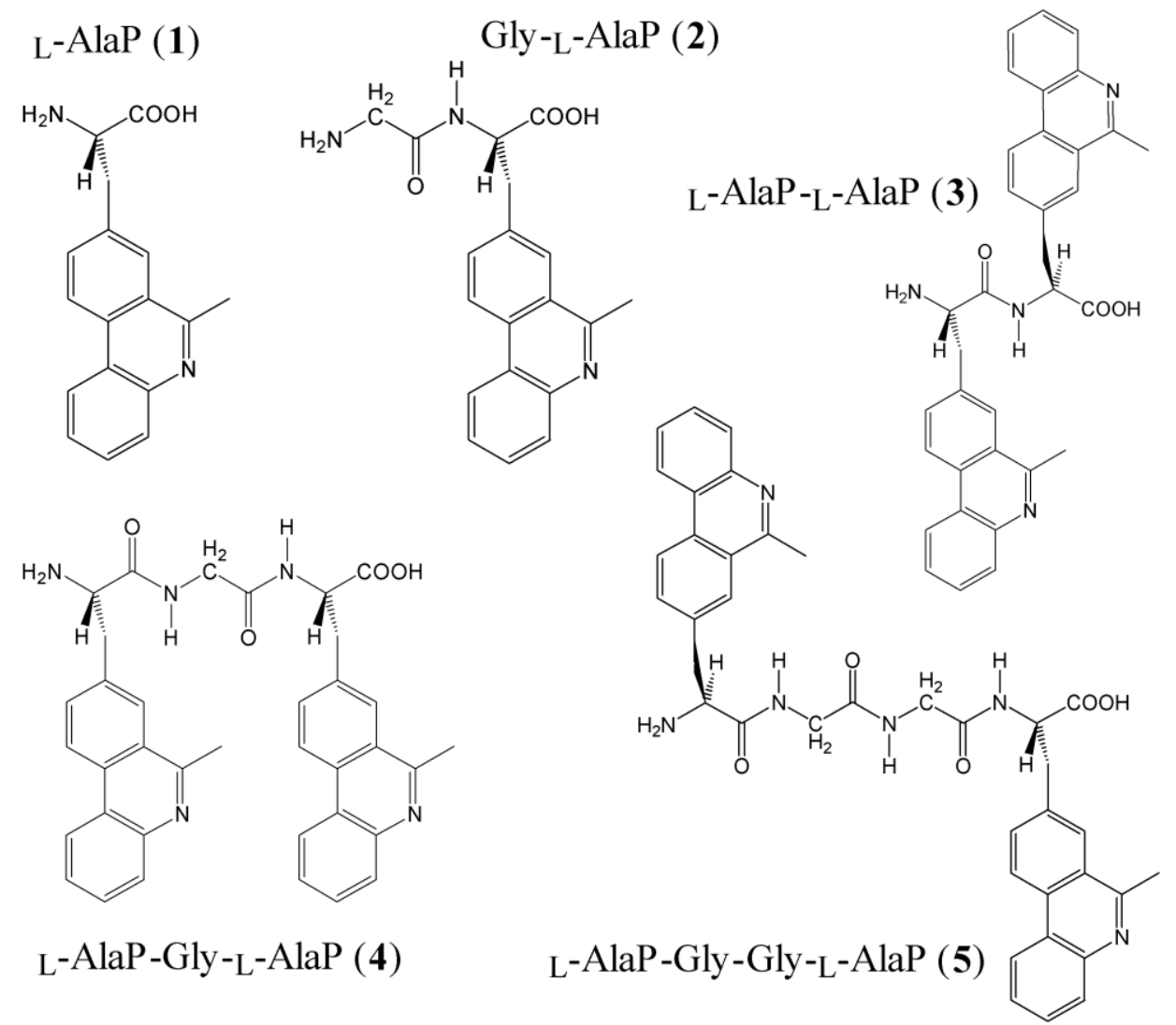

Scheme 1.<smiles>Cc1nc2ccccc2c2ccc(CC(NC(=O)OCc3ccccc3)C(=O)O)cc12</smiles><smiles>O=C(O)CNC(=O)O</smiles>

B

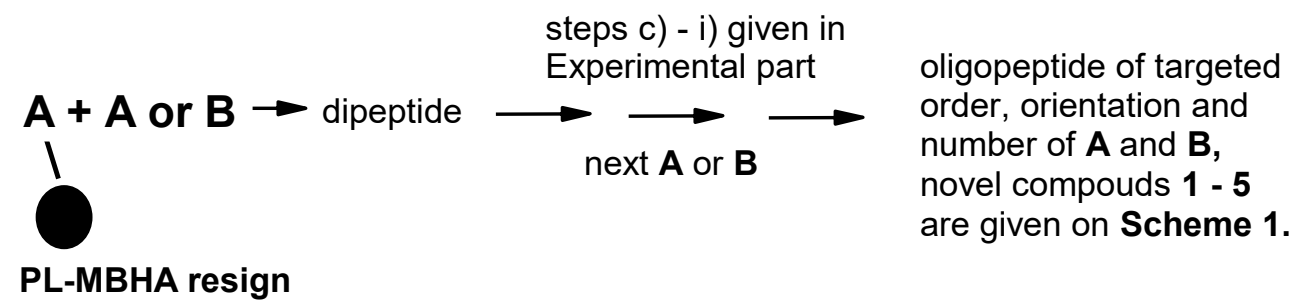

Scheme 2. 

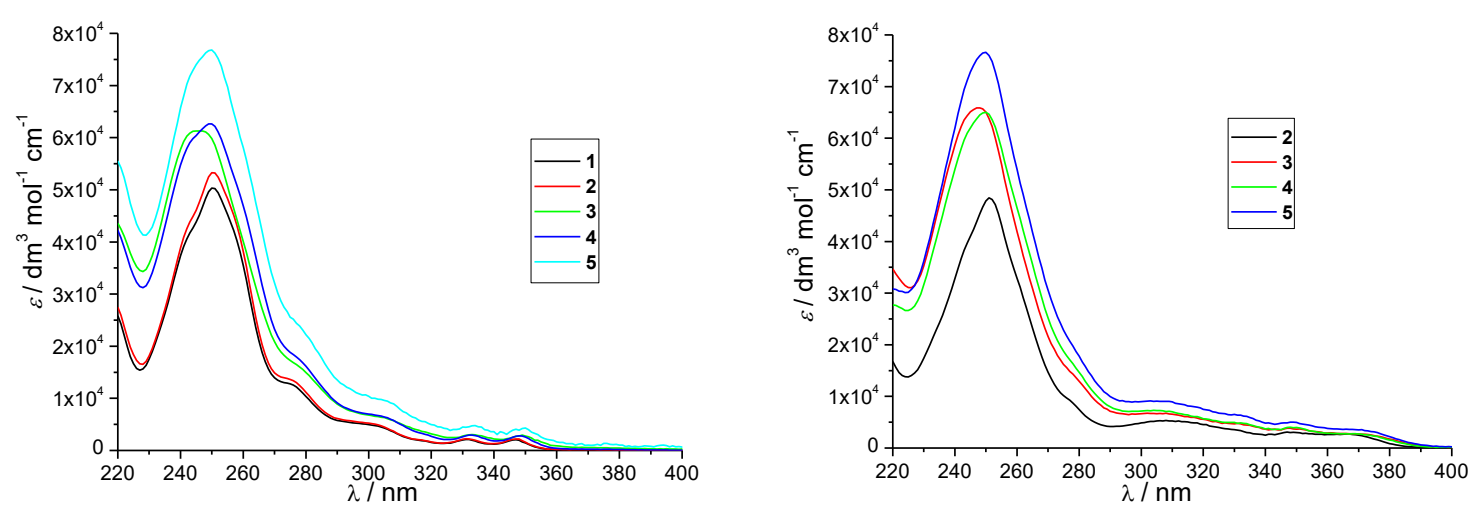

A

B

Figure 1.

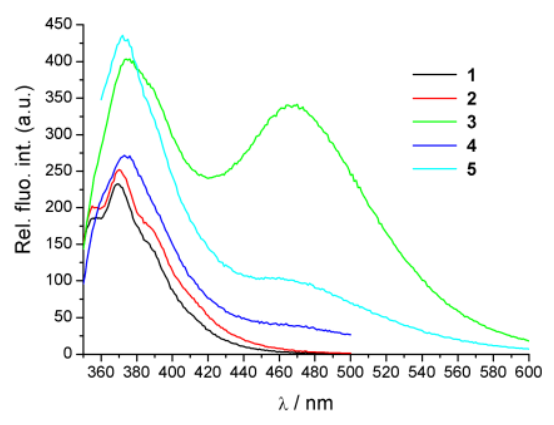

A

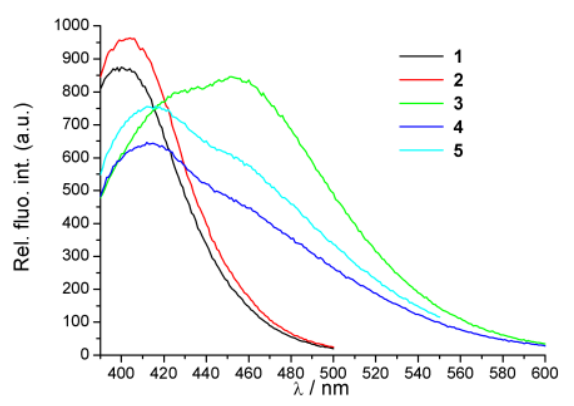

B

Figure 2.

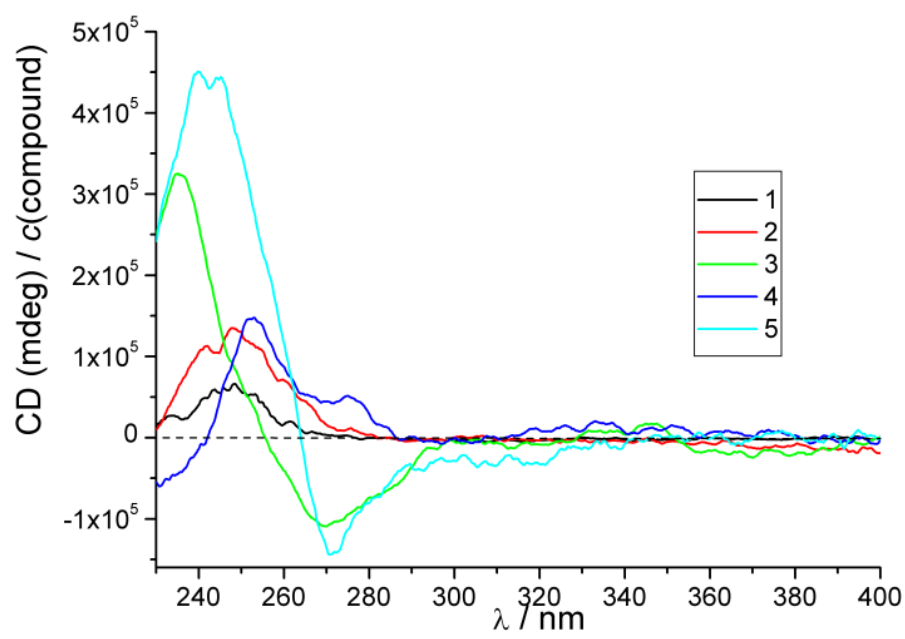

Figure 3. 

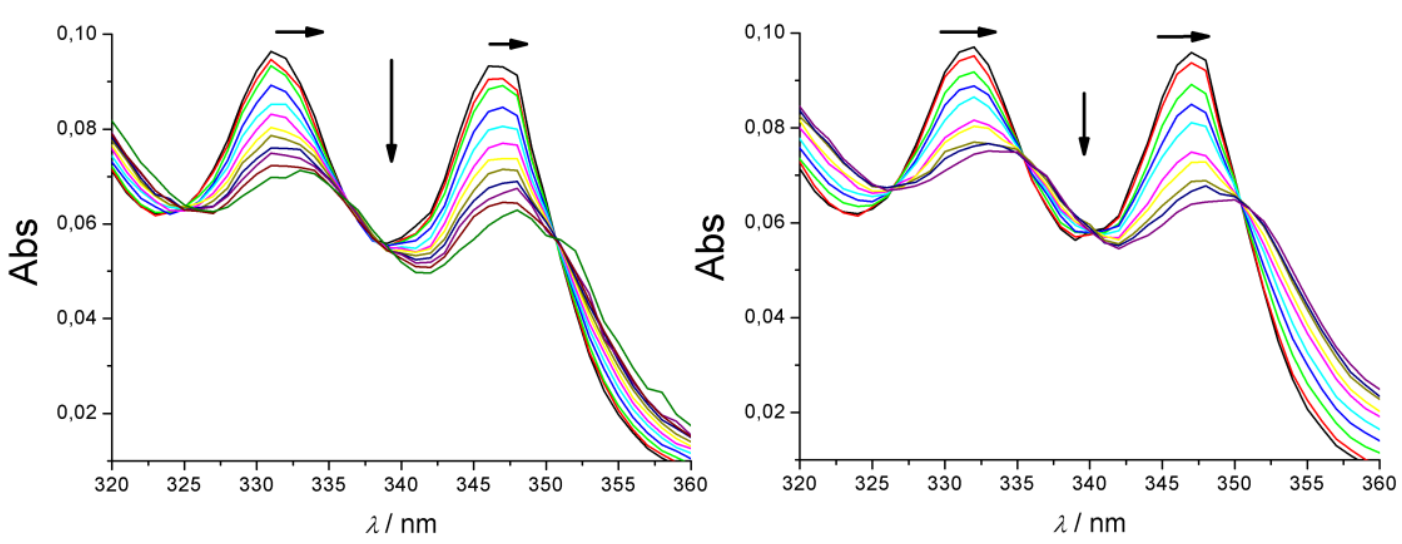

A

B

Figure 4.

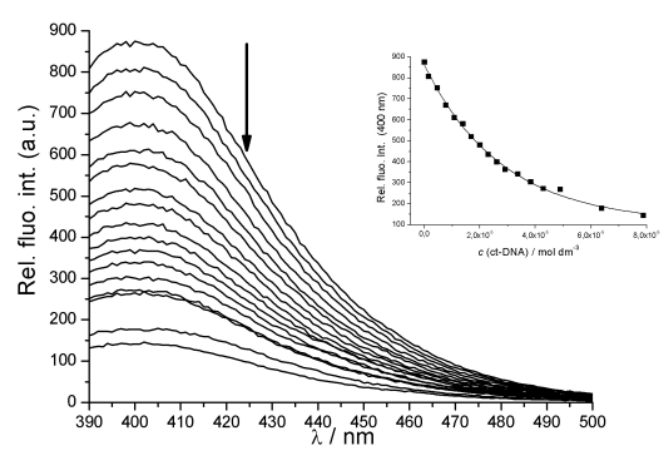

A

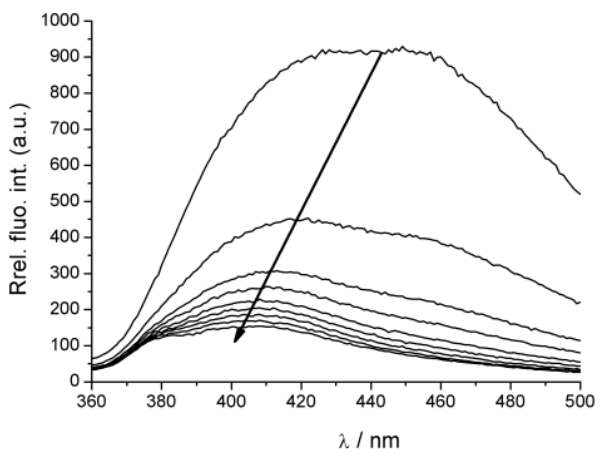

B

Figure 5. 